\title{
Triaxial Concrete Mixer Utilization Validity in Preparation of Fibro Concrete Mixture With Synthetic Fibers
}

\author{
Inga Emelyanova ${ }^{1 *} ; \mathrm{V}$. Asanov ${ }^{1}, \mathrm{~V}$. Shevchenko ${ }^{1}$ \\ ${ }^{1}$ Kharkov State University of Civil Engineering and Architecture, 61002, Kharkov (Ukraine)
}

The paper considers the preparation process of fibro concrete mixture with synthetic fibers by triaxial mixermachine of new generation, which operates in cascading mode. Triaxial mixer fibro concrete mixture preparation process technological parameters' diapasons are defined. Utilization validity of technological kit for preparation and transport of fibro concrete mixture is proven.

\section{Key words: fibro concrete mixture, triaxial mixer, synthetic fibers}

\section{INTRODUCTION}

Numerous researches, carried out in studying the abilities of concrete mixers that work in cascading system $[1,2]$, have shown great effectiveness of their utilization for fibro concrete mixture preparation [3].

For preparation of mixture with polyacrilic fiber the triaxial concrete mixer is used [4], whose constructive characteristics allow the preparation of high quality mix for various purposes: thin and thick mix, stabile fiber concrete and self-sealing one, and also the dry building mixtures.

Concrete mixer is equipped with working organ which contains three horizontal shafts (Fig. 1.a).

Two shafts (Upper and lower) are used for mixing the mixture components, and are equipped with blades that enable triaxial spatial mixture movement in the machine and smashing the soft agglomerates in malter components; central shaft makes the screw part which is equipped with blades in first mixer zone, blades are in second right mixer zone set up on the scroll.

For usage of gravitational forces and intensification of complex multicontour movement of concrete mix particles in cascading mode, the shafts are set at angle in vertical plane, in relation to the horizontal axis.

In the working process, this mixer enables a combination of two principles of mix components mixing in machine's operating space: gravitational and forced.

Triaxial mixer can be classified in the new generation concrete mixers, in cascading operational mode, which use the whole casing space.

Utilization degree check of these machines for fibro-concrete mixture preparation is carried out by introduction of polyacrylic fiber.

Polyacrylic fibers lenghts are $L_{1}=12 \mathrm{~mm}$ and $\mathrm{L}_{2}=$ $24 \mathrm{~mm}$, and diameter $\mathrm{d}_{\phi}=0,33 \mathrm{~mm}$. They are added to the dry, dosed mixture's solution components which, after mixing in 1st mixer zone by its operational organ, are directed to 2nd machine zone, where they are mixed with water needed. Ratio of water and cement in cement-sand mix preparation is $\mathrm{V} / \mathrm{C}=0.44$.
Triaxial concrete mixer ability estimate is performed by durability parameters of control samples of fibro-concrete on stress, which are formed in accordance with the planned experiment.

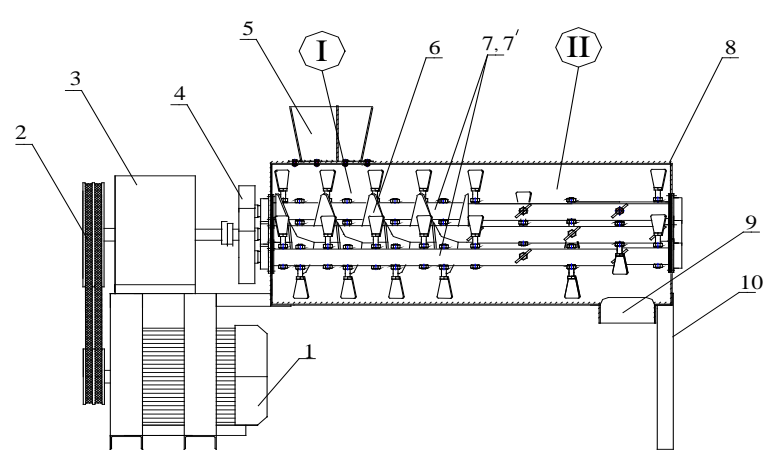

a) triaxial concrete mixer principle scheme

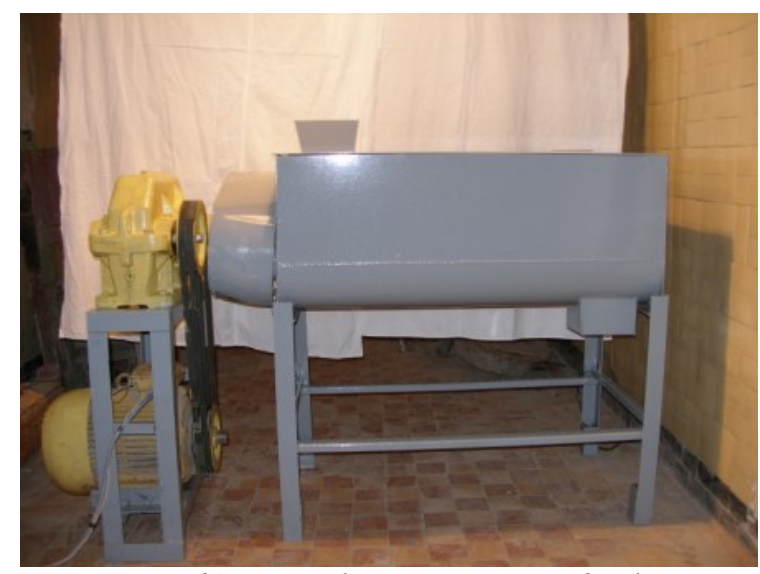

b) Triaxial concrete mixer display

Figure 1. Triaxial concrete mixer

1. electromotor; 2. V-belt; 3. reducer; 4. open toothed gear; 5. inlet hopper; 6. helix shaft; 7,7'. upper and lower shaft with blades; 8. concrete mixer casing; 9. draining tube; 10. construction; I-zone of concrete mixture dry components mixing; II- zone of concrete mixture preparation with the given water-cement ratio. 
For performing the experiment there was chosen the second order orthogonal plan which provides equality of all co-variations between coefficients and regression equations, and gratest precision near the plan center, as well as the following parameters:

- Sand-cement ratio in mixture $\mathrm{C} / \mathrm{P}=1 / 3 \ldots \mathrm{C} / \mathrm{P}=1 / 4$ $\mathrm{X}_{1}$;

-Polyacrylic fiber content in $1 \mathrm{~m}^{3}$ - cement and sand mixture $\Phi \%=0 \% \ldots 1 \%-\mathrm{X}_{2}$;

- Fiber elements length, $L_{f}=0 \ldots 24 m m-X_{3}$.

In every series of experiment performing, the experiment was performed three times and middle value of response function was determined.

Regression equation determination and its adequacy check was carried out on in program "MathCAD-11 Professional".

Obtained regression equations in coordinate form are:

$$
\begin{aligned}
& Y=17,349-1,183 \cdot x_{1}-2,035 \cdot x_{2}-1,61 \cdot x_{3}+0,22 \cdot x_{1}^{2}-0,472 \cdot x_{2}^{2}-0,385 \cdot x_{3}^{2}+ \\
& +1,964 x_{1} \cdot x_{2}
\end{aligned}
$$

Figures from 2 to 4 show functional dependencies of fibro-concrete hardness on stress, 7 days old, depending on technological parameters of preparation process of concrete mixture with polyacrylic fibers.

Dependence $f_{s \check{z}}=f(C / P)$ is shown in fig. 2.

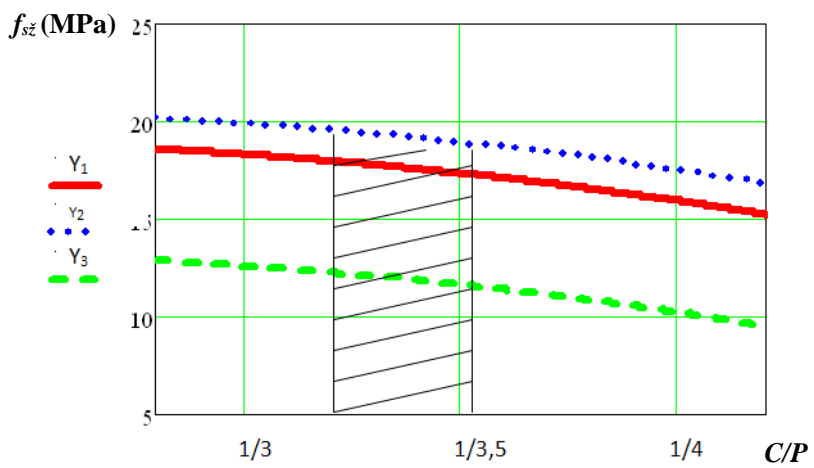

Figure 2. Stress hardness of fibro-concrete sample pieces in dependance of cement-sand ratio in mixture

$Y_{1}$ - at fibro elements content $F=0,5 \%$ and at their length $L_{f 1}=12 \mathrm{~mm} ; Y_{2}-$ at fibro elements content $F=0 \%$ and at their length $L_{f 2}=0 \mathrm{~mm} ; Y_{3}$ - at fibro elements content $F=1 \%$ and at their length $L_{f 3}=24 \mathrm{~mm}$

Dependence $f_{s \check{z}}=f(F, \%)$ is shown in fig. 3 . Hardness $f_{\breve{s} \check{~}}=f\left(L_{f}\right)$ is shown in fig. 4.

According to the shown graphical dependences, determined were the rational diapasons of fibro-concrete mixture aplication process technological parameters research influences that enable to obtain the high hardness concrete.
The listed diapasons are: for cement-sand ratio in mixture - $\mathrm{C} / \mathrm{P}=1 / 3 \ldots 1 / 3,2$; percentual content in polyacrylic fiber mixture, $\mathrm{F} \%=0,1 \ldots 0,3$; fibro elements length $\mathrm{L}_{\mathrm{f}}=6 . .12 \mathrm{~mm}$.

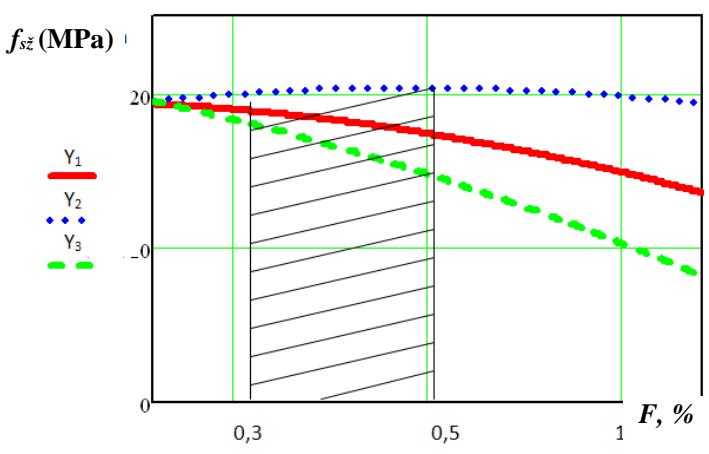

Figure 3. Stress hardness of fibro-concrete sample pieces depending on percentage of polyacrylic fibers content

$Y_{1}$ - for cement-sand ratio in mixture, $C / P=1 / 3,5$ and fibro elements length $L_{f 1}=12 \mathrm{~mm} ; Y_{2}$ - for cement-sand ratio in mixture, $C / P=1 / 3$ and fibro elements length $L_{f 2}=0$ $\mathrm{mm} ; Y_{3}-$ for cement-sand ratio in mixture, $C / P=1 / 4$ and fibro elements length $L_{f 3}=24 \mathrm{~mm}$.

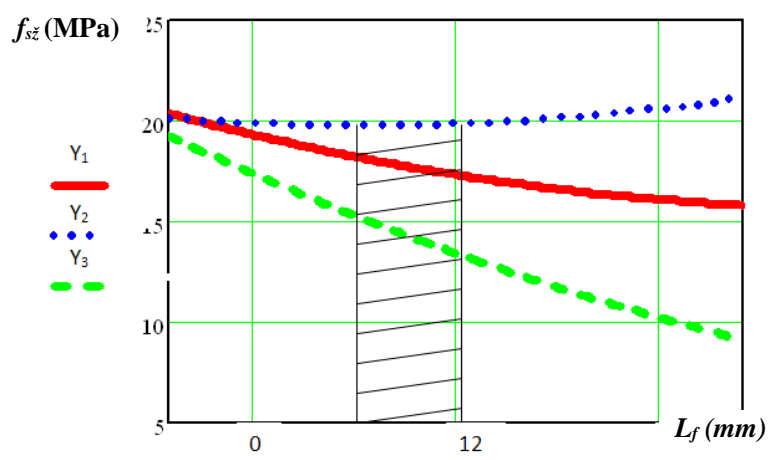

Figure 4. Stress hardness of fibro-concrete samples in dependance of fibro elements length

$Y_{1}-$ for cement-sand ratio in mixture, $C / P=1 / 3,5$ and fibro elements content $F=0.5 \% ; Y_{2}$ - for cement-sand ratio in mixture, $C / P=1 / 3$ and fibro elements content $F=0 \% ; Y_{3}$

- for cement-sand ratio in mixture, $C / P=1 / 4$ and fibro elements content $F=1 \%$;

In figures from 5 to 7 are shown the dependences of concrete hardness on stress depending on technological parameters of concrete mixture preparation process in triaxial concrete mixer, 28 days old.

Dependence $f_{\mathrm{s} \breve{z}}=f(C / P)$ is shown in figure 5 .

Regression equations have the form:

$$
\begin{aligned}
& Y=24,746-1,687 \cdot x_{1}-2,884 \cdot x_{2}-2,4 \cdot x_{3}-0,322 \cdot x_{1}^{2}-0,675 \cdot x_{2}^{2}+ \\
& +0,561 \cdot x_{3}^{2}-2,663 x_{1} \cdot x_{2}
\end{aligned}
$$




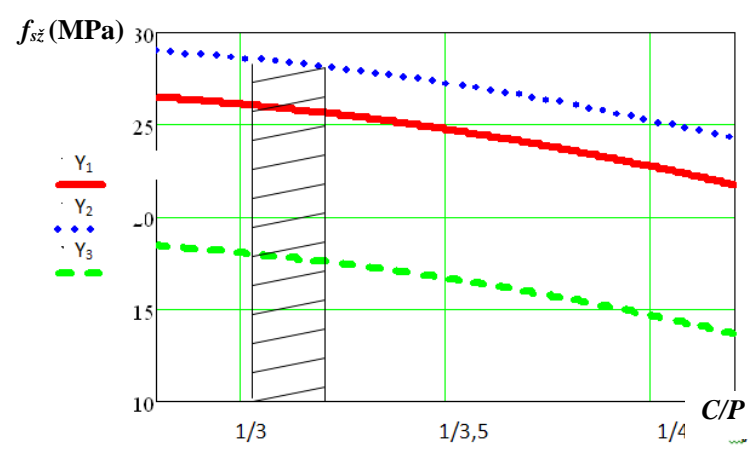

Figure 5. Fibro-concrete samples hardness in dependence of cement-sand ratio in mixture

$Y_{1}-$ at fibro elements content $F=0,5 \%$ and their length $L_{f 1}=12 \mathrm{~mm} ; Y_{2}-$ at fibro elements content $F=0 \%$ and their length $L_{f 2}=0 \mathrm{~mm} ; Y_{3}-$ at fibro elements content $F=1 \%$ and their length $L_{f 3}=24 \mathrm{~mm}$;

Dependence $f_{s \check{z}}=f(F, \%)$ is shown in fig. 6 .

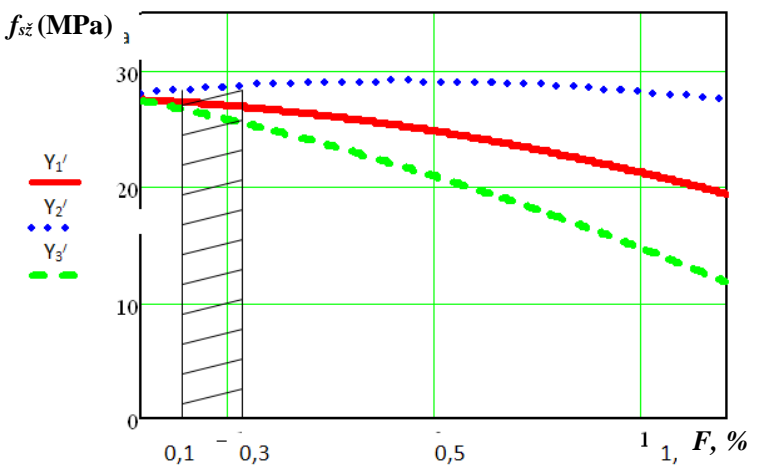

Figure 6. Fibro-concrete test samples hardnes on stress in dependence of polyacrylic fibers content percentage

$Y_{1}$ - for cement-sand ratio in mixture $C / P=1 / 3,5$ and fibroelements length $L_{f 1}=12 \mathrm{~mm} ; Y_{2}$ - for cement-sand ratio in mixture $C / P=1 / 3$ and fibroelements length $L_{f 2}=0$ $\mathrm{mm}$; $Y_{3}-$ for cement-sand ratio in mixture $C / P=1 / 4$ and fibroelements length $L_{f 3}=24 \mathrm{~mm}$;

Dependence $f_{s \breve{z}}=f\left(L_{f}\right)$ is shown in fig. 7 .

Simultaneously, according to graphic dependences, it should be mentioned that operating diapasons of researched technological parameters for providing the highest concrete hardness are: cement-sand ratio in mixture $-\mathrm{C} / \mathrm{P}=1 / 3 \ldots 1 / 3,2$; percent content in polyacrylic fibers mixture $\mathrm{F} \%=0,1 \ldots 0,3$; fibro elements length $\mathrm{L}_{\mathrm{f}}=6 . .12 \mathrm{~mm}$.

Also, of interest are the research results for determination of fibro concrete mix components mixing time influence on mixture hardness indicators. Research results are shown in Table 1. Fig. 8 shows the fibroconcrete stress hardness dependence on mixture components mixing time.
Graphic dependence in fig. 8 shows that at length of polyacrylic fibers $L_{f}=12 \mathrm{~mm}$ already after $15 \mathrm{~s}$ it enables their even distribution at $80 \%$ volume of total prepared mixture.

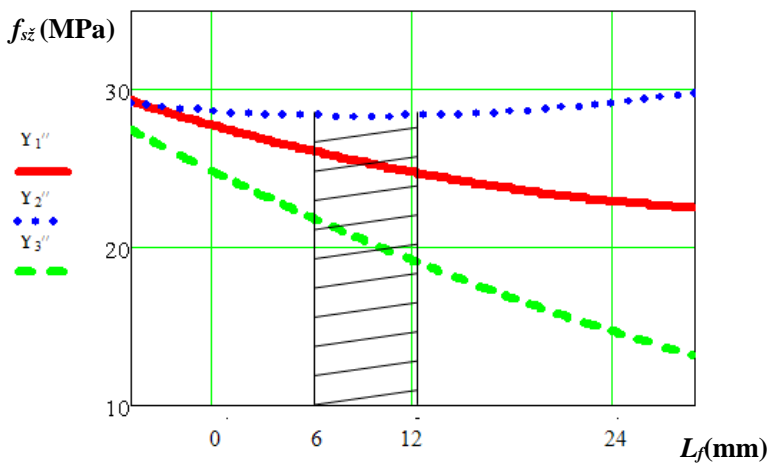

Figure 7. Fibro-concrete test samples stress hardness depending on fibro elements length

$Y_{1}$ - for cement-sand ratio in mixture $C / P=1 / 3,5$ and fibro elements content $F_{1}=0,5 \% ; Y_{2}-$ for cement-sand ratio in mixture $C / P=1 / 3$ and fibro elements content $F_{2}=0 \% ; Y_{3}-$ for cement-sand ratio in mixture $C / P=1 / 4$ and fibro elements content $F_{3}=1 \%$

Table 1. Research results for determination of fibroconcrete mix components mixing time influence on mixture hardness indicators

\begin{tabular}{ccc}
\hline $\begin{array}{c}\text { Mixing time, } \\
{[\mathrm{s}]}\end{array}$ & $\begin{array}{c}\text { Samples } \\
\text { middle mass, } \\
{[\mathrm{g}]}\end{array}$ & $\begin{array}{c}\text { Samples middle } \\
\text { stress hardness, } \\
{[\mathrm{MPa}]}\end{array}$ \\
\hline 15 & 1920 & 8,5 \\
30 & 2125 & 12,3 \\
45 & 2171 & 12,5 \\
60 & 2198 & 12,8 \\
90 & 2065 & 12,3 \\
\hline
\end{tabular}

In $45 \mathrm{~s}$ of mixing there is obtained the complete distribution of fibers through out the whole volume. In this way, the performed researches have shown expediency and efficiency of concrete mixer triaxial shaft utilization for preparation of fiber-concrete mixture with synthetic fibers on the example of polyacrylic fiber utilization. However, for performed researches the previously sliced fibers on special tools were used. Technological preparation process organization, at previously sliced fiber elements utilization, is characterized by a series of deficiencies: usage of supplementary tools for fibers cutting, their laying into special container for loading and emptying the mixing equipment with appearance of induration of some elements. 


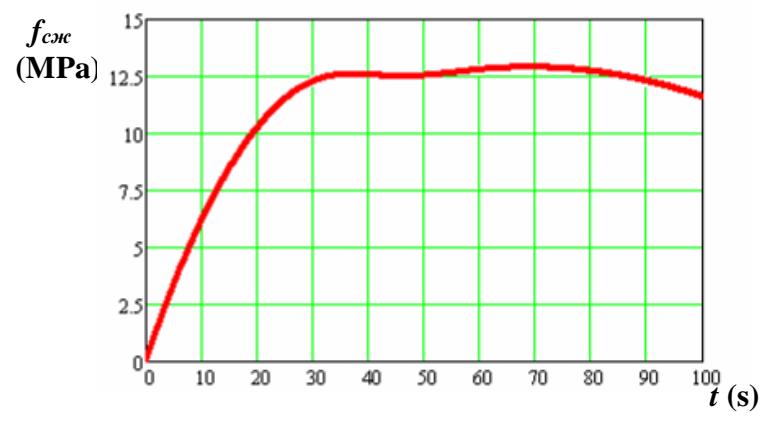

Figure 8. Fibro-concrete stress herdness dependence $\left(L_{f}=6 \mathrm{~mm}, F=0,3 \%\right)$ on mixing time at mixture preparation on triaxial concrete mixer

It is suggested to prepare fiber-concrete mixture by usage of technological kits which allow to, at single workplace, produce all technological combinations with their full time mixing. For fulfilling these aims it is suggested to use the technological kits wit triaxial concrete mixer. Research results are shown above. Principle scheme of this kit is shown in fig. 9.

The small dimension kit (fig. 9) includes the belt transporter 1, which delivers the material and doses the mixture components that come onto its belt from the inlet hopper 2; synthetic fiber slot-cutter 3, which provides the fibers cutting and their dosing into the triaxial concrete mixer 4; concrete pump with laminar shutters 5, designed for transport of ready fibro-concrete mixture. Dosing of supplementary air under pressure at slot-cutter operating 3 , provides the mobile compressor ПКС-5,25. The kit's specific characteristic is the availability of special construction of slot-cutter which is designed for cutting the fiber elements from synthetic fiber. The use of given small dimension kit enables the time combining of all technological operations in process of preparation and transport of fibro-concrete mixture that provides a high level of technological process organization.

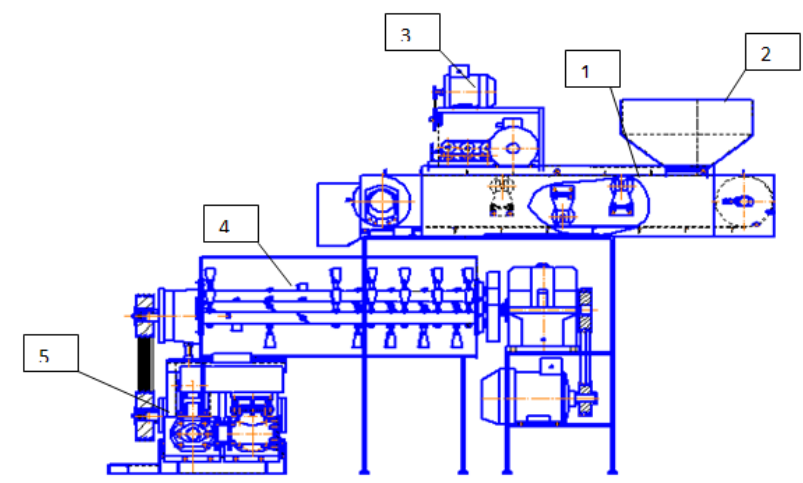

Figure 9. Principle scheme of technological kit for preparation and transport of concrete mixture with synthetic fibers

1 - belt transporter; 2- belt transporter's bunker; 3 synthetic fiber slot-cutter 4- triaxial concrete mixer; 5 concrete pump with laminar shutters.

Main advantage of this kit's operation is a possibility of complete elimination of fibers' induration during preparation in mixer's operating space, and obtaining, at the outlet, the fibro-concrete mixture with high level of homogeneity. In this way, the small dimension equipment in the form of triaxial concrete mixer and technological kits, enables the preparation and transport of high homogeneity fibro-concrete mixture at the very building site.

\section{REFERENCES}

[1] Emeljanova I.A. Contemporary building mixtures and equipment for their preparation. Учеб. Textbook / Emeljanova I.A., Dobrohodova O.V., Anišćenko Timčenko A.I., 2010 - 146 c. (In Russian)

[2] Emeljanova I.A. Concrete mixers that operate in cascading mode. Monograph / Emeljanova I.A., A.I. Anišćenko, Evel S.M., Blaško V.V., Dobrohodova O.V., Melencov N.A. - Harkov: Тим Паблиш Груп, $2012-146$.

[3] Emeljanova I.A. Equipment for preparation and sealing of fibro-concrete mixture. Monograph / Emeljanova I.A., Ševčenko V.JU., Asanov V.V. Харьков: Тим Паблиш Груп, 2015 - 124.

[4] Blaško V.V. Triaxial concrete mixer for preparation of малоподвижных concrete mixtures: dissertation, candidate of technical sciences 050502 / Blaško Vladimir Vladimirovič. - X., 2007 - 159 c. 